\title{
Linfoma difuso de células B grandes primario de clivus: Reporte de un caso
}

\section{Primary diffuse large B-cells lymphoma of the clivus: Case report}

\author{
Matías Álvarez B. ${ }^{1}$, Luciano Tapia Ch. ${ }^{2}$, Pablo Villanueva G. ${ }^{3}$, Claudio Callejas C. ${ }^{1}$
}

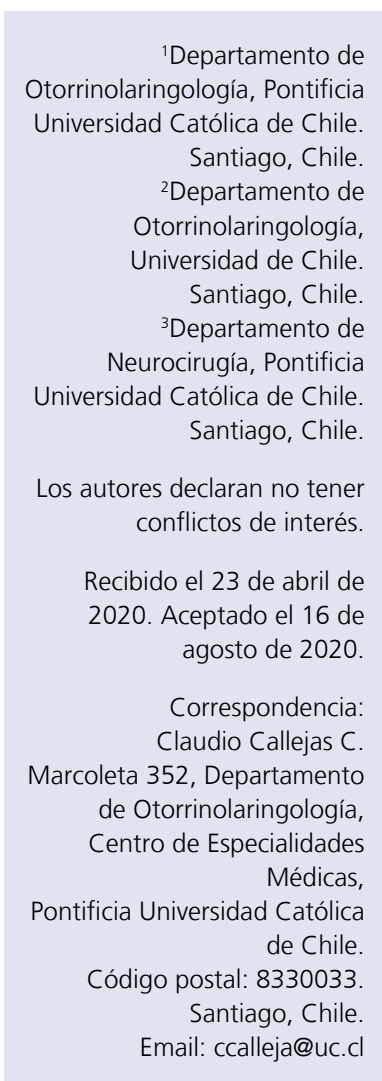

\section{Resumen}

El clivus corresponde a una región de la fosa craneal posterior conformada por la unión del cuerpo del hueso esfenoidal y la porción basilar del hueso occipital, siendo sus lesiones poco frecuentes. Dentro de las lesiones clivales las más frecuentes son los cordomas (40\%), condrosarcomas, adenomas ectópicos, linfomas, entre otros. Los linfomas no Hodgkin primario de hueso corresponden a una presentación extranodal, muy infrecuente en adultos, constituyendo sólo un $1 \%$ a $2 \%$ de estos en la base de cráneo. Se presentan principalmente con cefalea, síntomas B, diplopia y parestesias trigeminales. El origen primario clival es una manifestación aún más infrecuente, siendo su principal síntoma la cefalea. La sospecha debe ser alta requiriendo neuroimágenes, luego biopsia ya sea endoscópica o abierta. El manejo es con quimioterapia R-CHOP con un 67\% de respuesta completa, $16 \%$ de detención de la progresión y $16 \%$ de progresión pese a tratamiento.

Palabras clave: linfoma, clivus, fosa posterior, base de cráneo, cirugía endoscópica.

\begin{abstract}
The clivus corresponds to a posterior cranial fossa region formed by the union of the body of the sphenoid bone and the basilar portion of the occipital bone, being its pathology very rare. Among the clival lesions, the most frequent are chordomas (40\%), chondrosarcomas, ectopic adenomas, lymphomas, among others. Primary bone non-Hodgkin lymphomas correspond to an extranodal presentation, which is very infrequent in adults, while the skull base presentation corresponds only to $1 \%$ to $2 \%$. They present mainly with headache, $B$ symptoms, diplopia, and trigeminal paresthesia. The primary clival origin is an even more infrequent manifestation, with headache being its main symptom. The clinical suspicious must be high, requiring neuroimaging, then an endoscopic or open surgery biopsy. Management is standardized with $\mathrm{R}$-CHOP chemotherapy with a $67 \%$ of complete response, $16 \%$ stop of progression and $16 \%$ progression despite treatment.

Keywords: lymphoma, clivus, posterior fossa, skull base, endoscopic surgery.
\end{abstract}

\section{Caso Clínico}

Se presenta el caso de una mujer de 66 años con antecedente de diabetes mellitus tipo 2 que consultó a medicina general por cuadro de 6 meses de evolución de cefalea de intensidad progresiva (primer episodio), sin fiebre. Se solicitó estudio con tomografía computada (TC) de cerebro que mostró lesiones osteolíticas de clivus y cóndilos occipitales por lo que fue derivada a equipo de cirugía de base de cráneo para estudio.
La evaluación clínica descartó oftalmoplegia y déficits neurológicos focales. La evaluación endoscópica nasal evidenció mucosa de aspecto sano, sin rinorrea patológica ni masas. Se solicitó resonancia magnética (RM) de cerebro y cavidades paranasales que evidenció una lesión ósea sustitutiva difusa de base de cráneo hipointensa en T1W e isointensa en T2W con compromiso del clivus, ala mayor del esfenoides a izquierda y cóndilos occipitales. Además, se observaba infiltración de la mucosa del seno esfenoidal por contigüidad y compromiso de 

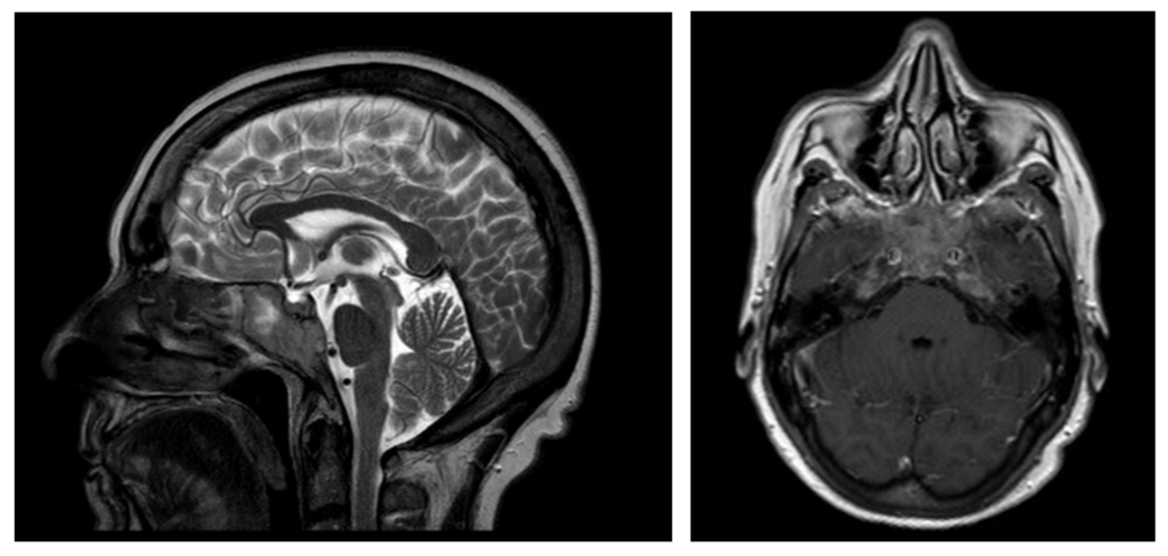

Figura 1. Resonancia magnética potenciada en T2, corte sagital y axial, que evidencia lesión infiltrante de clivus con compromiso esfenoidal y occipital.

los forámenes redondos y vidianos asociados a adenopatías cervicales múltiples en grupo yugular alto (Figura 1).

Se realizó una biopsia incisional vía abordaje transesfenoidal endoscópico (esfenoidotomías transnasales bilaterales asociadas a septectomía posterior), observándose lesión blanquecina friable en ambos senos esfenoidales que se envió a biopsia intraoperatoria informada como compatible con tumor maligno de células grandes con sospecha de linfoma no Hodgkin (LNH). Posterior a la cirugía, la paciente evolucionó favorablemente, siendo dada de alta a los 2 días para completar estudio de estadificación e inicio de quimioterapia en forma ambulatoria.

La biopsia definitiva evidenció tejido cerebral y óseo extensamente infiltrado por neoplasia linfoide con patrón infiltrativo difuso. El estudio inmunohistoquímico fue reactivo para CD20, CD30, CD79a, BCL6, MYC (40\%) y MUM-1; y negativo para CD3, CD5 y CD56, con Ki67 > 80\% compatible con LNH de estirpe B. El inmunofenotipo por citometría de flujo confirmó síndrome linfoproliferativo de estirpe B de células grandes, con inmunoglobulina de superficie (-) y probable origen en centro germinal CD $10+$.

\section{Discusión}

El clivus se ubica en la fosa craneal posterior en la cara interna de la base del cráneo, está conformado por la unión del cuerpo del hueso esfenoidal con la porción basilar del hueso occipital; limita hacia anterior con el dorso de la silla turca, hacia posterior con el agujero magno y hacia lateral con la porción petrosa del hueso temporal ${ }^{1}$. Las lesiones del clivus son poco comunes. Dentro de las más frecuentes encontramos los cordomas (40\%), condrosarcomas, metástasis de tumores de órgano sólido, adenomas ectópicos, plasmocitomas solitarios, quiste neuroentérico, granuloma eosinofílico, tumor de células gigantes, displasia fibrosa, quiste óseo aneurismático, osteoblastoma, osteocondromas, hemangiomas y linfomas ${ }^{2}$.

El linfoma corresponde a la proliferación tumoral maligna de células linfoides. Dentro de su clasificación se pueden agrupar en linfoma de Hodgkin (LH) y no Hodgkin y a su vez en compromiso nodal y extranodal ${ }^{3}$. El LNH primario de hueso corresponde a una presentación extranodal y muy infrecuente en adultos, constituyendo sólo un 1\%-2\% de estos $^{4}$, desde el punto de vista etiológico el linfoma difuso de células B grandes (LDCB) es el más frecuente (56\%), seguido por linfoma células B folicular (15\%) y linfoma células B zona marginal $(6 \%)^{5}$.

El LNH primario de base de cráneo es una manifestación aún menos común, siendo su edad de presentación habitual en la sexta década de la vida. Dentro de la sintomatología inicial encontramos síntomas B, tales como fiebre, sudoración nocturna y baja de peso $(25 \%)$, cefalea $(29 \%)$, diplopía con 
compromiso del VI par (52\%), parestesias faciales trigeminales $(38 \%)$ y parálisis facial (25\%), entre otros ${ }^{6}$. La revisión más grande hasta la fecha de Marinelli y cols. ${ }^{5}$ incluye 48 casos reportados en la literatura internacional de LNH primario de base de cráneo, de los cuales el $56 \%$ corresponden a LDCB y $48 \%$ tienen ubicación anterolateral (seno cavernoso, Meckel). La sospecha debe ser alta requiriendo neuroimágenes $y$, posteriormente, biopsia mediante la técnica de preferencia del equipo tratante, entre las que se incluyen cirugía endoscópica, abordajes transeptales bajo visión microscópica y cirugía abierta. En la última década ha habido una evolución desde los abordajes abiertos transeptales, como el transeptal-subesfenoidal ${ }^{7}$, a procedimientos menos invasivos como el endoscópico transesfenoidal-transclival ${ }^{8}$. Una vez establecido el diagnóstico el tratamiento de elección es quimioterapia con 4 ciclos de metotrexato, ciclofosfamida, doxurrubicina, vincristina y prednisona (R-CHOP). Se describe un 67\% respuesta completa, $16 \%$ de detención de la progresión y $16 \%$ de progresión pese a tratamiento. La sobrevida global de LDCB de base de cráneo a 1, 5 y 10 años corresponde a $85 \%$, $72 \%$ y $66 \%$ respectivamente ${ }^{5}$.

Los linfomas primarios del clivus son lesiones extremadamente infrecuentes. Actualmente se encuentran escasos casos descritos en la literatura. Yokote y cols. ${ }^{9}$ describen una revisión de 10 casos publicados hasta el año 2012, siete corresponden a sexo femenino, la edad de presentación promedio fue de 63 años, 8 presentaron compromiso de pares craneanos y 6 histología de LDCB. El manejo incluyó protocolos R-CHOP asociados o no a radioterapia. Por otro lado, Marinelli y cols. ${ }^{5}$ solo describen el origen en clivus en 6 de 48 casos primarios de base de cráneo, correspondientes al 13\% del total de la muestra. Meng y cols. ${ }^{10}$ presentan 8 linfomas primarios de base de cráneo en población China, de los cuales 4 correspondían a origen clival. El 100\% debutó con cefalea asociada a compromiso de pares craneanos y el diagnóstico se realizó mediante abordaje transesfenoidal endoscópico en la totalidad de los casos.

En conclusión, de acuerdo a lo presentado en nuestro caso clínico y revisión de la litera- tura el LDCB primario de clivus corresponde a una entidad muy poco frecuente. Resulta importante considerarlo como diagnóstico diferencial en el estudio de lesiones de clivus y en el estudio de pacientes con compromiso de VI par. El manejo actual se encuentra estandarizado y con buenos resultados de sobrevida.

\section{Bibliografía}

1. Hofmann E, Prescher A. (2011). The Clivus. Clinical Neuroradiology. 2012;22(2):123-139.

2. Gagliardi F, Boari N, Mortini P. Solitary nonchordomatous lesions of the clival bone: differential diagnosis and current therapeutic strategies. Neurosurg Rev. 2013;36: 513-522.

3. Swerdlow SH, Campo E, Harris NL, Jaffe ES, Pileri $\mathrm{SA}$, Stein $\mathrm{H}$, et al. World Health Organization, International Agency for Research on Cancer WHO classification of tumours of haematopoietic and lymphoid tissues. Revised 4th edition ed. World Health Organization classification of tumours. International Agency for Research on Cancer; 2017.

4. Pesce A, Acqui M, Cimatti M, Caruso R, Wierzbicki V, Raco A. Primary lymphomas of the skull base from a neurosurgical perspective: review of the literature and personal experience. J Neurol Surg. 2017;78: 6066.

5. Marinelli JP, Modzeski MC, Lane JI, Van Gompel JJ, Stokken JK, Thanarajasingam G, et al. Primary Skull Base Lymphoma: Manifestations and Clinical Outcomes of a Great Imitator. Otolaryngol Head Neck Surg. 2018;159(4):643-649.

6. Tsai VW, Rybak L, Espinosa J, Kuhn MJ, Kamel OW, Mathews F, et al. Primary B-cell lymphoma of the clivus: Case report. Surg Neurol. 2002;58:246-50.

7. Stott C, Olavarría C, Bustos P. Abordajes alternativos para tumores del clivus. Rev Otorrinolaringol Cir Cabeza Cuello. 2002;62:169-174.

8. Snyderman CH, Pant H, Carrau RL, Prevedello D, Gardner P, Kassam AB. What are the limits of endoscopic sinus surgery?: the expanded endonasal approach to the skull base. Keio J Med. 2009;58(3):152-160.

9. Yokote A, Tsuboi Y, Fukuhara K, Tsugawa J, Inoue $\mathrm{H}$, Aoki M, et al. Primary clivus diffuse large B cell lymphoma presenting with posterior neck pain and bilateral abducens nerve palsy. Rinsho Shinkeigaku. 2012;52(4):245-50.

10. Meng, X, Zhou, S, Wan, J. Primary Lymphoma of the Skull Base in the Chinese: Clinical, Radiological, Pathological, and Therapeutic Experience in a Series of 8 Patients. World Neurosurgery. 2019;123:e171-e179. 